\title{
Prospective Assessment of the Rockall Risk Scoring System in Egyptian Patients with Upper Gastrointestinal Bleeding
}

\author{
Mohga A. Reda1, Iman F. Montasser ${ }^{1}$, Shereen A. Saleh ${ }^{2 *}$, Azza M. Hassan ${ }^{3}$, \\ Alaa Eldein I. Ewis ${ }^{4}$ \\ ${ }^{1}$ Department of Tropical Medicine, Faculty of Medicine, Ain Shams University, Cairo, Egypt \\ ${ }^{2}$ Department of Internal Medicine, Faculty of Medicine, Ain Shams University, Cairo, Egypt \\ ${ }^{3}$ Department of Community, Environmental and Occupational Medicine, Faculty of Medicine, Ain Shams \\ University, Cairo, Egypt \\ ${ }^{4}$ Department of Tropical Medicine, Theodor Bilharz Research Institute, Cairo, Egypt \\ Email: ${ }^{*}$ shereen saleh2014@hotmail.com
}

Received 30 April 2015; accepted 16 June 2015; published 19 June 2015

Copyright (C) 2015 by authors and Scientific Research Publishing Inc.

This work is licensed under the Creative Commons Attribution International License (CC BY).

http://creativecommons.org/licenses/by/4.0/

(c) (i) Open Access

\section{Abstract}

Background: One of the major challenges in managing acute upper gastrointestinal bleeding involves the identification of patients who are at high risk of rebleeding and death; conversely, the identification of patients who are suitable for early discharge and outpatient endoscopy is also important for effective resource. The use of Rockall system has been shown to represent accurate and valid predictor of rebleeding and death. The aim of this prospective study was to evaluate validity of Rockall score for prediction of rebleeding and mortality in Egyptian patients with upper gastrointestinal bleeding. Patients and Methods: 50 patients presented with upper GI bleeding were subjected to detailed clinical, laboratory, sonographic and endoscopic examination together with Rockall score calculation. Results: According to the findings of upper GI endoscopy patients were further subdivided into two subgroups as follows: Group $1(n=32)$ : Patients with portal hypertension manifested by variceal bleeding and/or portal hypertensive gastropathy; and Group $2(n=18)$ : other causes of acute upper gastrointestinal bleeding (peptic ulcer disease, Mallory Weiss syndrome...). Clinical condition of the patients was assessed after 48 hours and mortality was recorded. Rockall score was the highest in mortality group, and higher in rebleeding group than stable group $(P<\mathbf{0 . 0 1})$. Rockall score was higher in Child $C$ than Child $B$ and Child $A$ among hepatic patients $(P<0.01)$. The cutoff value of Rockall score $=3.5$ was the best for prediction of rebleeding with sensitivity $100 \%$, specificity $53 \%$, while the cutoff value $=6.5$ was the best for prediction of mortality with sensitivity $100 \%$ and $93.5 \%$ specificity. Conclusion: Rockall score is clinically useful in prediction of rebleeding and mortality in patients with upper gastrointestinal

${ }^{*}$ Corresponding author.

How to cite this paper: Reda, M.A., Montasser, I.F., Saleh, S.A., Hassan, A.M. and Ewis, A.E.I. (2015) Prospective Assessment of the Rockall Risk Scoring System in Egyptian Patients with Upper Gastrointestinal Bleeding. Open Journal of Gastroenterology, 5, 66-76. http://dx.doi.org/10.4236/ojgas.2015.56012 
bleeding. It can accurately differentiate between patients with stable condition that could be discharged from hospital and those who require hospitalization and this could help to minimize hospital stay and cost.

\section{Keywords}

\section{Upper Gastrointestinal Bleeding, Rockall Score, Portal Hypertension}

\section{Introduction}

Acute upper gastrointestinal bleeding (AUGIB) is common, costly, and potentially life-threatening medical emergency and requires prompt assessment and aggressive medical management [1].

Significant upper GI bleeding is often caused by hemorrhage from varices, ulcers, Dieulafoy lesions, MalloryWeiss tears and neoplasms [2].

Elderly patients and those with chronic medical diseases as liver cell failure, chronic renal failure and ischemic heart disease withstand AUGIB less well than younger, fitter patients, and have a higher risk of death [3] [4].

One of the major challenges in managing UGIB involves the identification of patients at high risk of rebleeding and death; conversely, the identification of patients who are suitable for early discharge and outpatient endoscopy is also important for effective resource use [5]. Similar to other common medical conditions, risk scores have been developed to try and identify those at lower or higher risk of poor outcome [6].

An ideal risk score is one that is easy to calculate, accurate for relevant outcomes and can be measured early after presentation with AUGIB [7].

The most commonly used risk scoring system in UGIB is the Rockall score [5] (Table 1). The score was developed to assess the risk of death and rebleeding following presentation with UGIB and incorporate patient age, hemodynamics, comorbidities and endoscopic findings [8].

This study aims to assess the validity of the Rockall score for the prediction of rebleeding and death in Egyptian patients with upper gastrointestinal bleeding.

\section{Patients and Methods}

This prospective, study included 50 Egyptian patients collected from the Inpatient Tropical, Internal Medicine Departments, Endoscopy Unit, Ain Shams University Hospitals and Theodor Bilharz Research Institute, Cairo, Egypt between May 2014 to December 2014. The study was approved by the Ethics Committee of Ain Shams University Hospitals, Cairo, Egypt in accordance with local research governance requirements. In accordance with the ethical standards laid down in the 1964 Declaration of Helsinki and all subsequent revisions. The trial was registered with the federal clearinghouse for randomized trials: ClinicalTrials.gov (NCT02405286). Informed written

Table 1. Rockall risk scoring system [9].

\begin{tabular}{|c|c|c|c|c|}
\hline \multicolumn{5}{|c|}{ Score } \\
\hline Variable & 0 & 1 & 2 & 3 \\
\hline Age & $<60$ years & $60-79$ years & $\geq 80$ years & \\
\hline Shock & $\begin{array}{l}\text { "No shock" } \\
\text { Systolic BP >100 } \\
\text { Pulse }<100\end{array}$ & $\begin{array}{l}\text { "Tachycardia” } \\
\text { Systolic BP > } 100 \\
\text { Pulse }>100\end{array}$ & $\begin{array}{l}\text { "Hypotension" } \\
\text { Systolic BP < } 100\end{array}$ & \\
\hline Comorbidity & No major comorbidity & & $\begin{array}{l}\text { Cardiac failure, IHD, } \\
\text { any major comorbidity }\end{array}$ & $\begin{array}{l}\text { Renal failure, liver failure, } \\
\text { disseminated malignancy }\end{array}$ \\
\hline Diagnosis & $\begin{array}{l}\text { Mallory-Weiss tear, } \\
\text { no lesion identified, no SRH }\end{array}$ & All other diagnosis & Malignancy of upper GI bleeding & \\
\hline Major SRH & None or dark spot only & & $\begin{array}{l}\text { Blood in upper GI tract, } \\
\text { adherent clot, } \\
\text { visible or spurting vessel }\end{array}$ & \\
\hline
\end{tabular}

$\mathrm{BP}=$ blood pressure; IHD = ischemic heart disease; $\mathrm{SRH}=$ stigmata of recent hemorrhage 
consent was obtained from each participant before enrollment in the study. Sample size calculation: A total sample size of 50 achieves $82 \%$ power to detect a change in sensitivity from 0.5 to 0.85 using a two-sided binomial test and $65 \%$ power to detect a change in specificity from 0.5 to 0.7 using a two-sided binomial test. The target significance level is 0.05 . The actual significance level achieved by the sensitivity test is 0.0352 and achieved by the specificity test is 0.0410 . The prevalence of unfavorable outcomes (re-bleeding or death) is 0.3 .

\subsection{Inclusion Criteria}

The patients were eligible for this study if they had any history or symptoms of acute upper GI hemorrhage during the past 24 hours before emergency admission. Acute UGIH is defined as hematemesis, passage of melena, or hematochezia with clear evidence of an upper GI source of brisk bleeding. Peptic ulceration defined as any lesion seen to possess unequivocal depth. Erosions classified as any other break in the mucosa. A cherry-red spot, red whale marks and hematocystic spots were considered being equivalent to a dark spot. Rebleeding defined as overt fresh bleeding or a fall in blood pressure after initial stabilization, or a fall in Hb of more than $2 \mathrm{~g}$ within 24 hours. This method of scoring and these definitions are identical to the initial Rockall study and in accordance with the original National Audit [10].

\subsection{Methods}

According to the findings of upper GI endoscopy the patient group was further subdivided into two subgroups as follows:

Group 1 ( $n=32$ ): Patients with portal hypertension manifested by variceal bleeding and/or portal hypertensive gastropathy (PHG).

Group 2 ( $n=18)$ : other causes of acute upper gastrointestinal bleeding (peptic ulcer disease, Mallory Weiss syndrome...).

All included patients were subjected to the following: 1) Full history taking as regard symptoms and signs of GI hemorrhage, co-morbidity and relevant drug history with thorough clinical examination for signs of bleeding (pulse rate, blood pressure), pallor and abdominal examination for organomegaly, abdominal masses and ascites.

2) Laboratory assessment including: Complete blood count and coagulation profile: prothrombin time (PT), partial thromboplastin time (PTT) and international normalized ratio (INR), liver function tests: aspartate aminotransferase (AST), alanine amino-transferase (ALT), total and direct serum bilirubin, total protein and serum albumin; Renal function tests: serum sodium, serum potassium, serum creatinine and blood urea nitrogen (BUN) by standard lab tests.

3) Blood, plasma or platelet transfusion as required.

4) All patients with suspected varices received a 50- $\mu$ g i.v. Bolus of octreotide (Novartis Pharmaceutical) on admission, followed by an infusion of $1 \mathrm{mg}$ in $55 \mathrm{ml}$ of normal saline at a rate of $3 \mathrm{ml} / \mathrm{h}$.

5) Upper gastrointestinal tract endoscopy: using Pentax endoscopy was done and findings were recorded. If stigmata of recent hemorrhage were seen, esophageal varices were either injected with ethanolamine or banded, depending on the clinical setting and availability. For patients with peptic ulcer disease in the presence of stigmata of recent hemorrhage, endoscopic injection therapy (adrenaline 1:100,000) together with either thermal coagulation or hemo-clips was done depending on the clinical setting and availability. For patients with gastric varices, endoscopic injection with histoacryl was done.

6) Prospective assessment together with Rockall score calculation was done for all cases.

7) Child-Pugh scores were calculated for hepatic patients with esophageal varices or portal HTN.

8) Abdominal ultrasonography was done for identification of radiological criteria of portal hypertension (spleen size, portal vein diameter, ascites). Equipment used: Hitachi, EUB-5500.

Finally, data was collected pertaining to the duration of inpatient stay, complications that occurred as well as a calculated Rockall score.

\subsection{Statistical Analysis}

Quantitative data were presented as minimum, maximum, mean and standard deviation. Qualitative data were presented as number and percentage. Student t test was used to compare quantitative data between two groups and one-way ANOVA was used when more than two groups were to be compared then Post Hoc test was used 
to detect the difference between individual groups. ROC curve was used to measure diagnostic validity and determine the best cut off value for some variables. $\mathrm{P}$ value $<0.05$ was considered significant and $<0.01$ was considered highly significant.

\section{Results}

The mean age for the patients included in the study was $56.92 \pm 11.54$. Minimum Rockall score among the studied patients was 1 while the maximum score was 9 with (mean $\pm \mathrm{SD}=3.96 \pm 2.18$ ), most of patients were males (76\%) and 38 of them were hepatic (76\%). As regard the Child score among the hepatic patients, most patients were Child C and Child B (47.4\%), (36.8\%) respectively. Twenty-six patients (52\%) had ascites. Ten patients (20\%) suffered from encephalopathy. Regarding shock, ten patients $(20 \%)$ were shocked at time of presentation. Twenty-nine patients (58\%) required blood transfusion (Table 2).

Regarding Co-morbidity, (22\%) of patients (eleven patients) suffered from co-morbid conditions, four patients (8\%) had ischemic heart disease (IHD) and seven (14\%) had chronic renal failure (CRF).

The mean of $\mathrm{Hb}$ of the studied patients at time of presentation was $8.44 \pm 2.05 \mathrm{gm} / \mathrm{dl}$ (Range between 4.4 $-13.3)$. The mean of serum albumin in the studied patients was $2.76 \pm 0.72 \mathrm{gm} / \mathrm{dl}$. INR ranged between (1.00 -3.42) with mean $1.36 \pm 0.36$ (Table 3 ).

\begin{tabular}{cccc} 
Table 2. Description of patients' characteristics $(\mathrm{N}=50)^{\dagger}$. & & \\
\hline \multirow{2}{*}{ Gender } & Male & 37 & $74.0 \%$ \\
& Female & 13 & $26.0 \%$ \\
Diagnosis & Hepatic & 38 & $76.0 \%$ \\
& Non hepatic & 12 & $24.0 \%$ \\
Child score & Child A & 6 & $15.8 \%$ \\
& Child B & 14 & $36.8 \%$ \\
& Child C & 18 & $47.4 \%$ \\
Co-morbidity & Yes & 11 & $22.0 \%$ \\
& No & 39 & $78.0 \%$ \\
Ascites & Yes & 26 & $52.0 \%$ \\
& No & 24 & $48.0 \%$ \\
Encephalopathy & Yes & 10 & $20.0 \%$ \\
& No & 40 & $80.0 \%$ \\
Blood transfusion & Yes & 29 & $58.0 \%$ \\
Signs of Shock & No & 21 & $42.0 \%$ \\
& Yes & 10 & $20.0 \%$ \\
& No & 40 & $80.0 \%$ \\
\hline a & & & \\
\hline
\end{tabular}

${ }^{\dagger}$ Values are given as number (percentage).

Table 3. Description of important lab results`.

\begin{tabular}{ccccc}
\hline & Minimum & Maximum & Mean & SD \\
\hline Albumin (gm/dl) & 1.60 & 4.80 & 2.7660 & 0.72972 \\
Bilirubin (mg/dl) & 0.10 & 34.00 & 2.8720 & 5.48564 \\
Prothrombin (sec) & 11.30 & 38.40 & 15.3540 & 4.11191 \\
INR & 1.00 & 3.42 & 1.367 & 0.3654 \\
Hb (gm/dl) & 4.40 & 13.30 & 8.4460 & 2.05458 \\
WBCs (/mm $\left.\mathbf{m m}^{\mathbf{3}}\right)$ & 2.40 & 38.20 & 10.2800 & 7.19512 \\
Platelets $\left(\mathbf{m m}^{\mathbf{3}}\right)$ & 25.00 & 359.00 & 127.4000 & 72.72172 \\
\hline
\end{tabular}

${ }^{\dagger}$ Values are given as mean \pm standard deviation; Hb, Hemoglobin; WBCs, white blood cell count. 
Regarding the cause of bleeding diagnosed by endoscopy, summarized in Table 4, (18\%) of patients had grade II esophageal varices (OV), grade IV OV was found in six patients (12\%). In eleven patients (22\%) an ulcer was the cause of bleeding. Three cases $(6 \%)$ needed injection sclerotherapy for esophageal spurter. One case showed GAVE and another showed Dieulafoy lesion. Regarding stigmata of recent bleeding, (34\%) of patients (seventeen patients) had stigmata of recent bleeding as spurter, visible vessel and blood clot (Table 4).

Rockall score among hepatic patients was $4.03 \pm 2.31$ and among non hepatic patients was $3.75 \pm 1.82$ and this was statistically non significant $(\mathrm{P}=0.70)$.

Regarding hepatic patient's condition after 48 hrs $(n=38)$, twenty seven patients $(71.1 \%)$ had stable condition after 48 hrs and discharged from hospital. Eight cases (21.1\%) rebleeded again while three cases (7.9\%) died.

Ten (83.3\%) of the non-hepatic patients $(\mathrm{n}=12)$ had a stable condition after $48 \mathrm{hrs}$ and were discharged from hospital. One case (8.3\%) had another attack of bleeding while one case (8.3\%) died due to advanced malignancy.

There was highly statistically significant difference regarding the Rockall score between (Child A \& Child C) and (Child B \& Child C) among the hepatic patients. However, there was no statistically significant difference in Rockall score between (Child A \& Child B). Mean of Rockall score in Child A, B and C were: (2.17 \pm 98$)$, (2.57 $\pm 1.55)$ and $(5.61 \pm 2.09)$ respectively with $P$ value $<0.01$ (Table 5).

High statistical significant difference regarding the Rockall score was found between (stable group and rebleeding group), (stable group and death group) and between (rebleeding group and death group) among all patients. Means of Rockall score in stable group, rebleeding group and death group were (3.14 \pm 1.60$)$, (5.67 \pm 1.94) and (7.75 \pm 0.96$)$ respectively with $P$ value $<0.01$ (Table 5).

\begin{tabular}{|c|c|c|}
\hline Endoscopic finding & N. & $\%$ \\
\hline Esophageal varices & 25 & 50.0 \\
\hline Grade I varix & 1 & 2.0 \\
\hline Grade II band ligation & 9 & 18.0 \\
\hline Grade III band ligation & 3 & 6.0 \\
\hline Grade IV band ligation & 6 & 12.0 \\
\hline Injection sclerotherapy of esophageal varices & 3 & 6.0 \\
\hline Post band ulcer & 3 & 6.0 \\
\hline Gastric varices & 9 & 18.0 \\
\hline Injection sclerotherapy of fundal varices & 9 & 18.0 \\
\hline Both of injection sclerotherapy of fundal varices and band ligation of esophageal varices & 3 & 6.0 \\
\hline Peptic ulcer bleeding & 11 & 22.0 \\
\hline Duodenal ulcer & 2 & 4.0 \\
\hline Gastric ulcer & 9 & 18.0 \\
\hline Other lesions & 2 & 4.0 \\
\hline GAVE & 1 & 2.0 \\
\hline Dieulafoy lesions & 1 & 2.0 \\
\hline Portal hypertensive gastropathy (PHG) & 9 & 18.0 \\
\hline Mild PHG & 6 & 12.0 \\
\hline Severe PHG & 3 & 6.0 \\
\hline Stigmata of recent bleeding & 17 & 34.0 \\
\hline
\end{tabular}

${ }^{\dagger}$ Values are given as number (percentage). 
Table 5. differences regarding Rockall score in different child scores, all patients 'condition and hepatic patients' condition after $48 \mathrm{~h}$.

\begin{tabular}{|c|c|c|c|c|c|}
\hline & & \multicolumn{2}{|c|}{ Rockall score } & \multirow{2}{*}{ ANOVA test } & \multirow{2}{*}{$P$ value } \\
\hline & & Mean & SD & & \\
\hline \multirow{3}{*}{ Child score } & Child A & 2.17 & 0.98 & & \\
\hline & Child B & 2.57 & 1.55 & 15.10 & $<0.01^{*}$ \\
\hline & Child C & 5.61 & 2.09 & & \\
\hline \multirow{3}{*}{ Patients condition after 48 hrs } & Stable & 3.14 & 1.60 & & \\
\hline & Re-bleeding & 5.67 & 1.94 & 20.45 & $<0.01^{*}$ \\
\hline & Death & 7.75 & 0.96 & & \\
\hline \multirow{3}{*}{ Hepatic patients' condition after 48 hrs } & Stable & 3.04 & 1.60 & & \\
\hline & Re-bleeding & 5.87 & 1.96 & 18.47 & $<0.018^{*}$ \\
\hline & Death & 8.00 & 1.00 & & \\
\hline
\end{tabular}

A high statistical significant difference regarding the Rockall score was found between (stable group \& re-bleeding group), (stable group \& death group) and between (recurrence group \& death group) among hepatic patients. Means of Rockall score in stable, rebleeding and death groups were (3.04 \pm 1.60$),(5.87 \pm 1.96)$ and $(8.00 \pm 1.00)$ respectively with P value $<0.01$ (Table 5).

ROC curve for validity of Rockall score for prediction of rebleeding among all patients shows that the Cut off value set at 3.5000 was the best with sensitivity $100 \%$, specificity $53.7 \%$, positive predictive value $=32.1 \%$, negative predictive value $=100 \%($ AUROC $0.775,95 \%$ CI: $0.637-0.913, \mathrm{P}=0.01)$ (Figure 1$)$.

ROC curve for validity of Rockall score for prediction of mortality, shows that the best Cut off value was 6.5000 with sensitivity $100 \%$, specificity $93.5 \%$, positive predictive value $=57.1 \%$, negative predictive value $=$ 100\% (AUROC 0.962, 95\% CI: 0.000 - 1.000, $\mathrm{P}=0.01$ ) (Figure 2).

While , ROC curve for validity of Rockall score for prediction of rebleeding among hepatic patients, showed that the best Cut off value was 3.5000 with sensitivity $100 \%$, specifity $60 \%$, positive predictive value $=40 \%$, negative predictive value $=100 \%$. (AUROC 0.800, 95\% CI: $0.657-0.943, \mathrm{P}=0.01$ ) (Figure 3), and ROC curve for validity of Rockall score for prediction of mortality among hepatic patients showed that the best Cut off value was 6.5000 with sensitivity $100 \%$, specifity $91.4 \%$, positive predictive value $=50 \%$, negative predictive value $=100 \%$. $($ AUROC 0.957, 95\% CI: $0.000-1.000, \mathrm{P}=0.01)($ Figure 4$)$.

\section{Discussion}

One of the major challenges in managing UGIB involves the identification of patients who were at high risk of rebleeding and death; conversely, the identification of patients who were suitable for early discharge and outpatient endoscopy is also important for effective resource use [5]. The Rockall score was developed to assess the risk of death and rebleeding following presentation with UGIB and incorporates patient age, hemodynamics, comorbidities and endoscopic findings [8].

Regarding the demographic characteristics for patients involved in the study, the majority of the study patients were males (76\%). As regards age, this study showed that, the mean age of studied patients was $56.92 \pm$ 11.54 years. This is similar to results of De Groot et al., who evaluated value of prediction scores in patients with suspected upper gastrointestinal bleeding, and found that the mean age of the studied patients was 65 (range 18 - 99) [11]. and that 63\% of their studied patients were males too. However, Salih et al. [12] analyzed prediction of morbidity and mortality presenting with upper gastrointestinal bleeding using Rockall score and reported the mean age of patients presented with UGIB was $44.60 \pm 15.31$ years.

Regarding Child-Pugh classification of hepatic patients, most hepatic patients included in this study were Child C (47\%) and Child B (36\%), which is similar to Morsy et al. [13] who stated that most of hepatic patients in their study were Child C (75\%) and B (12\%), but is different than Gonzalez-Gonzalez et al. [14] who stated that hepatic patients with Child C classification represent only (26\%) of patients. This could be explained by the 


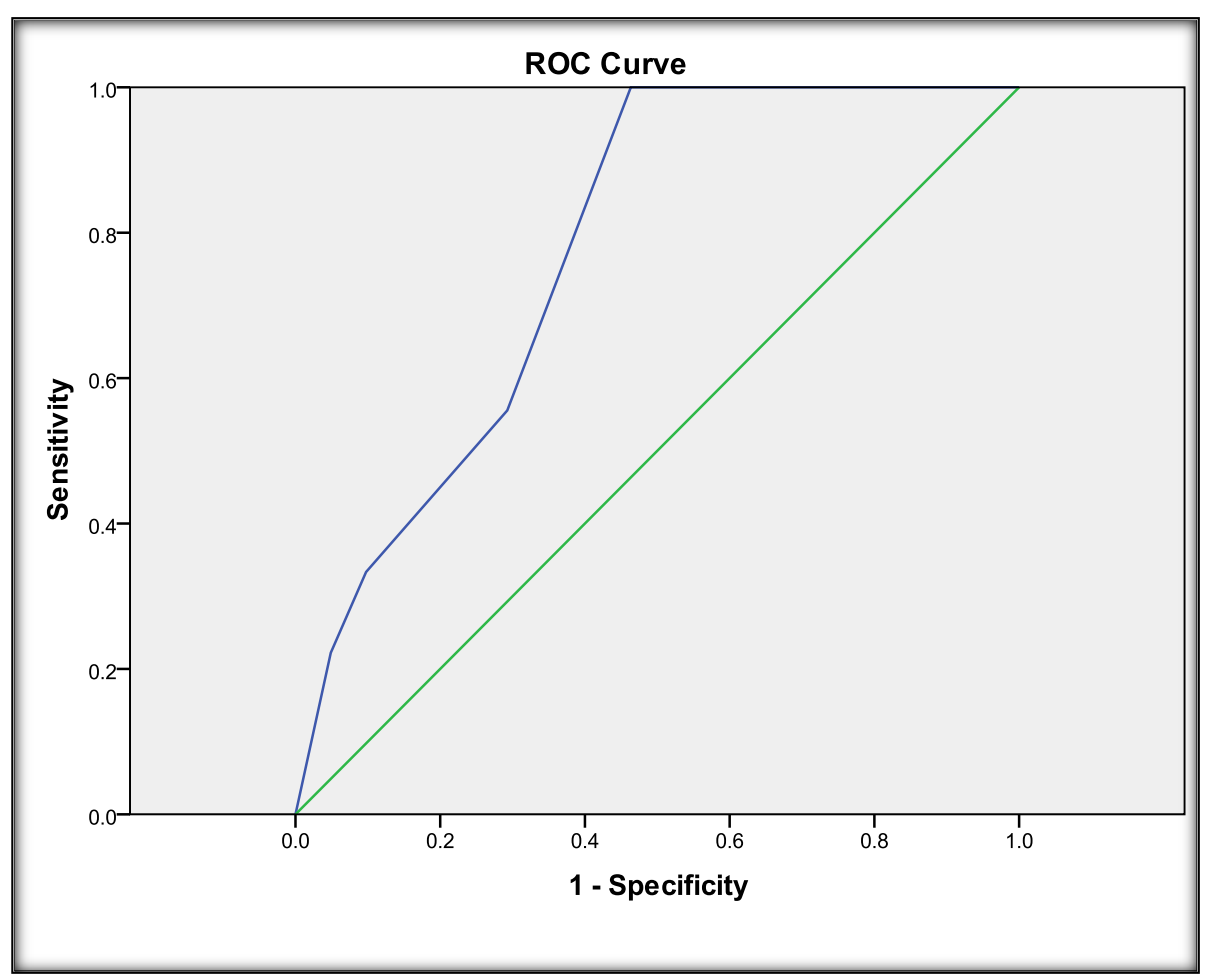

Figure 1. Show receiver operating curve (ROC) to determine the cut-off value for the best sensitivity and specificity of Rockall score in prediction of rebleeding among all patients. The area under the curve was 0.775 with the best cut-off value $=3.5$, where sensitivity was $100 \%$ and specificity was $53.7 \%$ (95\% confidence interval $=0.637-0.913)$.

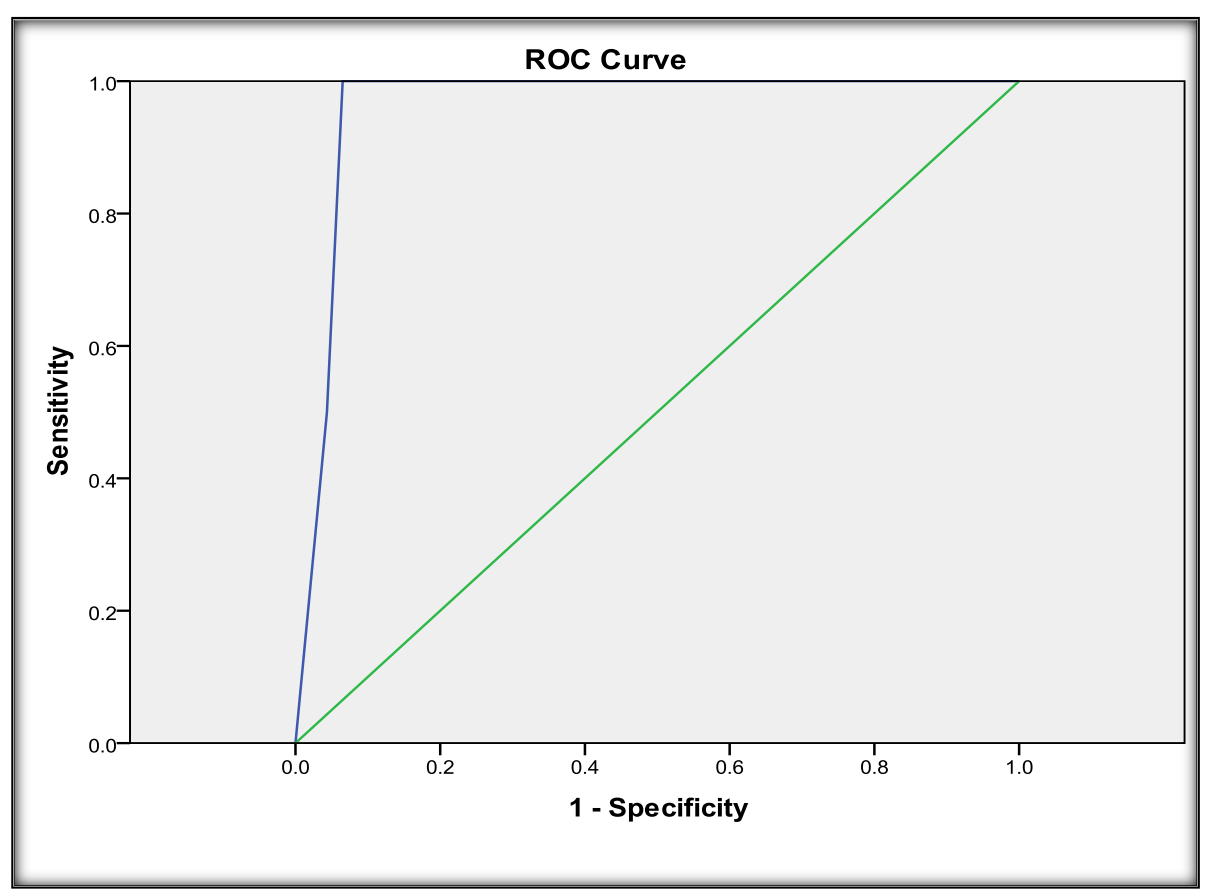

Figure 2. Show receiver operating curve (ROC) to determine the cut-off value for the best sensitivity and specificity of Rockall score in prediction of mortality among all patients. The area under the curve was 0.962 with the best cut-off value $=6.5$, where sensitivity was $100 \%$ and specificity was $93.5 \%$ (95\% confidence interval $=0.000-1.000)$. 


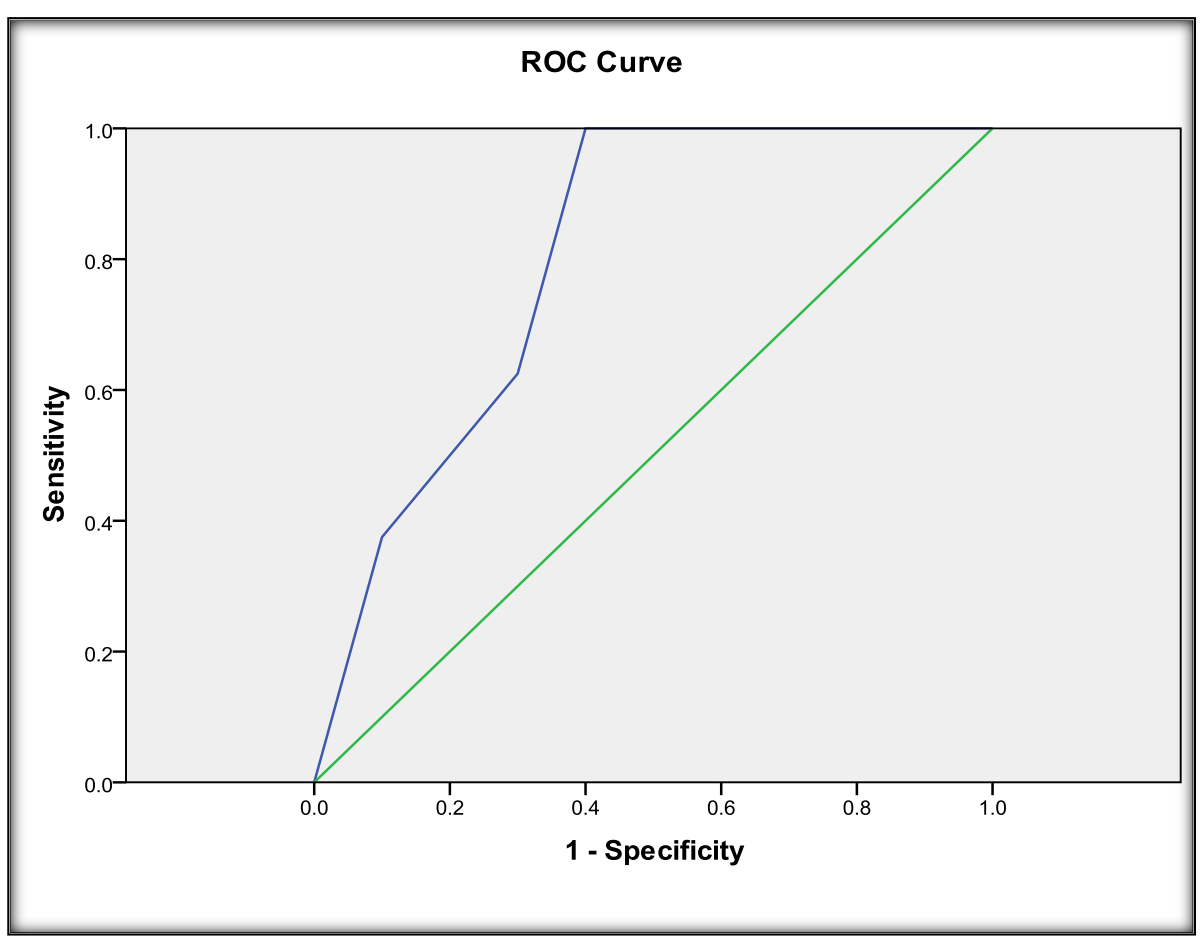

Figure 3. Show receiver operating curve (ROC) to determine the cut-off value for the best sensitivity and specificity of Rockall score in prediction of rebleeding among hepatic patients. The area under the curve was 0.800 with the best cut-off value $=3.5$, where sensitivity was $100 \%$ and specificity was $60 \%(95 \%$ confidence interval $=0.657-0.943)$.

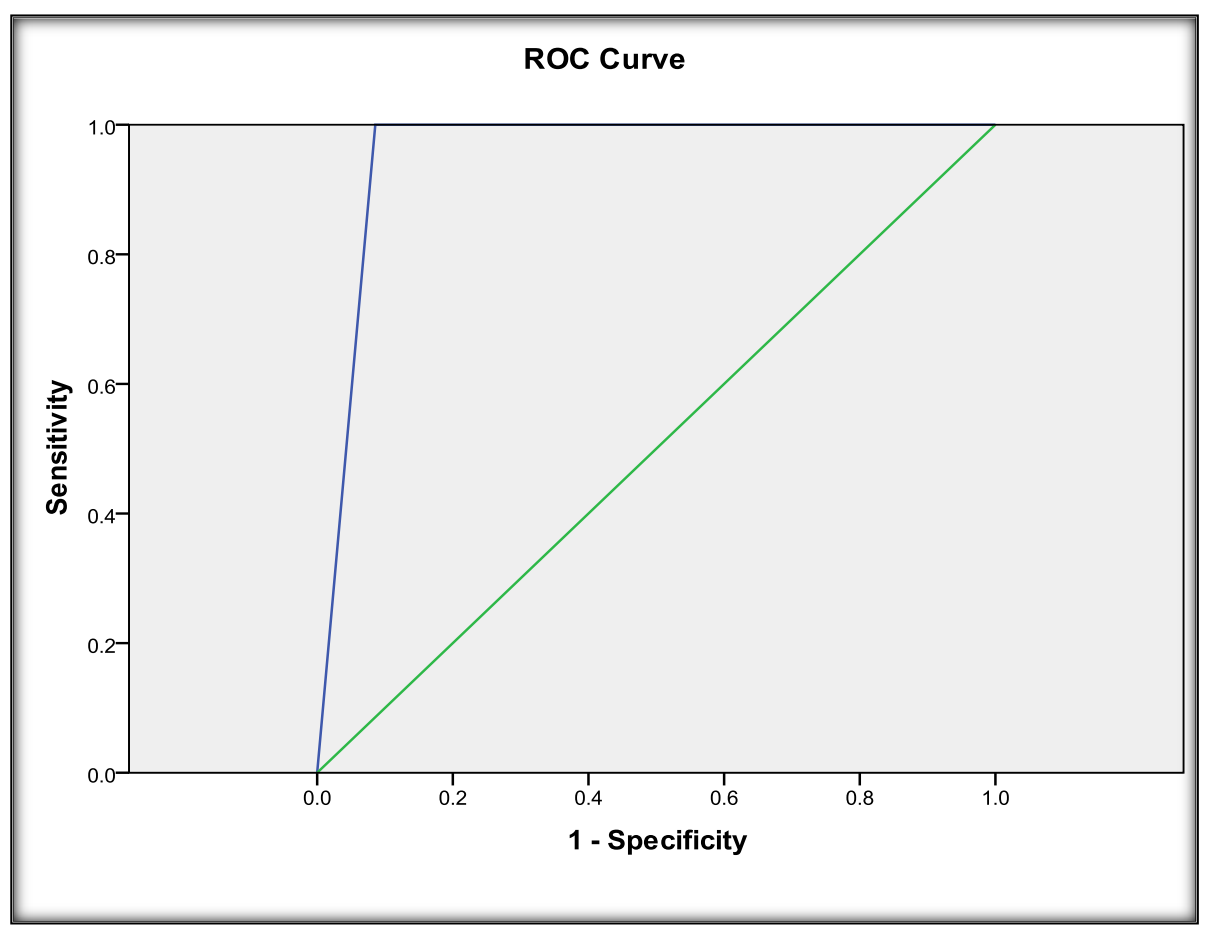

Figure 4. Show receiver operating curve (ROC) to determine the cut-off value for the best sensitivity and specificity of Rockall score in prediction of mortality among the hepatic patients. The area under the curve was 0.957 with the best cut-off value $=6.5$, where sensitivity was $100 \%$ and specificity was $91.4 \%(95 \%$ confidence interval $=0.000-1.000)$. 
high incidence of hepatic disease in our country, Egypt, with the highest prevalence of hepatitis C virus (HCV) in the world, estimated nationally at $14.7 \%$ [15] with great percent of decompensated liver cirrhosis.

Twenty percent of patients in this study were shocked during presentation and this finding is similar to a study conducted by Gado et al. [16] who stated that (18\%) were shocked during presentation. Blood transfusion was required to (58\%) of patients in the current study and this also similar to the study of De Groot et al. [11] who stated that blood transfusion was required for (58\%) of patients and supported with Morsy et al. [13] who stated in their study that blood transfusion was required for (61\%) of patients.

Regarding laboratory results, mean of $\mathrm{Hb}$ was $8.44 \pm 2.05 \mathrm{~g} / \mathrm{dl}$ that means that most of patients were anemic during presentation and this matches results of Kumar et al. [17] who stated that patients presented with upper gastrointestinal bleeding were anemic with mean of $\mathrm{Hb}(8.02 \pm 2.01 \mathrm{~g} / \mathrm{dl})$, and supported with De Groot $e t$ al. [11] as mean of patients' $\mathrm{Hb}$ in their study were $6.30 \pm 1.90 \mathrm{~g} / \mathrm{dl}$. As most patients included in our study were hepatic, laboratory findings of impairment of liver function were detected in the studied patients in the form of hypoalbuminemia, hyperbilirubinemia and increasing prothrombin time which is similar to the findings of Morsy et al. [13].

The cause of UGIH was bleeding esophageal varices in 50\% of patients of the current study, and peptic ulcer in $22 \%$. This is matching the study conducted by Anand et al. [18] who stated that (38.5\%) of patients were required band ligation of esophageal varices and peptic ulcer related bleeding represented (14.91\%) of patients.

$34 \%$ of patients of this study had stigmata of recent bleeding in their endoscopic examination, which is in some similarity to Balaban et al. [19] study in which most patients (58\%) had stigmata of recent bleeding.

Regarding hepatic patients' condition after 48 hrs, (21.1\%) of them rebleeded again while $(7.9 \%)$ of them died which match the results of Sanders et al. [20] who stated that rebleeding occurred in $19.4 \%$ of hepatic patients and $11 \%$ of them died.

The Child-Pugh scoring system has been widely accepted for prognostic assessment and for predicting mortality in patients with end-stage liver diseases [21]. On comparing the Rockall score in different Child-Pugh stages of hepatic patients in the current study, there was highly statistically significant difference in Rockall score between (Child A and C) and (Child B and C) with higher Rockall scores in patients with Child C liver cirrhosis. Both scores can predict mortality among hepatic patients and those with UGIH. Lee et al., [21], found that the Child-Pugh and Rockall scores were reliable measures of mortality risk in patients with first variceal bleeding.

On comparing between patients who haven't recurrent episode of bleeding, those who had another episode of UGIH in the following $48 \mathrm{~h}$ and those who died after the first attack, there was highly statistically significant difference in Rockall score with higher scores in those who died. This is matching the results of Balaban et al. [19] who stated that mean of Rockall score in mortality group was higher when compared with those without rebleeding.

Among hepatic patients, there was highly statistically significant difference in Rockall score between patients who hadn't recurrent episode of bleeding and those who had another episode of UGIH, and between patients who had another episode of UGIH and those who died after the first attack. This is in agreement with Sarwar et al. [22] who found higher Rockall score in mortality group than the group with recurrent bleeding who were higher than those who hadn't recurrent episode of bleeding. This is supported by Sanders et al. [20] results in which there were increase in incidence of rebleeding and mortality with higher levels of Rockall score.

Regarding Validity of Rockall score for prediction of re-bleeding among hepatic and non hepatic patients, the current study revealed that Rockall score has good predictive value of rebleeding in patients with upper gastrointestinal bleeding. This is in agreement with Wang et al. [23], Balaban et al. [19] and De Groot et al. [11] who stated that Rockall score has a good predictive value for rebleeding in patients with upper gastrointestinal bleeding. On the other hand, Vreeburg et al. [6] analyzed Validation of the Rockall risk scoring system in upper gastrointestinal bleeding and stated that Rockall score is poor in predicting rebleeding.

As Regard the validity of Rockall score for prediction of mortality among hepatic and none hepatic patients, our study revealed that Rockall score has good predictive value of mortality in patients with upper gastrointestinal bleeding and this is similar to Balaban et al. [19], Sanders et al. [20] and Vreeburg et al. [6], who stated that Rockall score has a good predictive value for mortality in patients with upper gastrointestinal bleeding.

\section{Conclusion}

The Rockall score is clinically useful, rapid and accurate in prediction of rebleeding and mortality in patients 
with upper gastrointestinal bleeding. It can differentiate between patients with stable condition that could be discharged from hospital and those who require hospitalization and this could help to minimize hospital stay and cost. Future trial on larger number of patients is emphasized.

\section{Conflicts of Interest}

There are no financial or other relations that could lead to a conflict of interest.

\section{Sources of Funding}

This research received no specific grant from any funding agency in the public, commercial or not-for-profit sectors.

\section{Ethics Statement}

This study was carried out after approval of Research and Ethics Committee of Ain Shams University, Cairo, Egypt in accordance with local research governance requirements. All human studies have been approved by the appropriate ethics committee and have therefore been performed in accordance with the ethical standards laid down in the 1964 Declaration of Helsinki and all subsequent revisions.

\section{References}

[1] Van Leerdam, M.E. (2008) Epidemiology of Acute Upper Gastrointestinal Bleeding. Best Practice Research Clinical Gastroenterology, 22, 209-224. http://dx.doi.org/10.1016/j.bpg.2007.10.011

[2] Enestvedt, B.K., Gralnek, I.M., Mattek, N., Lieberman, D.A. and Eisen, G. (2008) An Evaluation of Endoscopic Indications and Findings Related to Nonvariceal Upper-GI Hemorrhage in a Large Multicenter Consortium. Gastrointestinal Endoscopy, 67, 422-429. http://dx.doi.org/10.1016/j.gie.2007.09.024

[3] Charatcharoenwitthaya, P., Pausawasdi, N., Laosanguaneak, N., Bubthamala, J., Tanwandee, T. and Leelakusolvong, S. (2011) Characteristics and Outcomes of Acute Upper Gastrointestinal Bleeding after Therapeutic Endoscopy in the Elderly. World Journal of Gastroenterology, 17, 3724-3732. http://dx.doi.org/10.3748/wjg.v17.i32.3724

[4] Hearnshaw, S., Logan, R., Lowe, D., Travis, S.P., Murphy, M.F. and Palmer, K.R. (2011) Acute Upper Gastrointestinal Bleeding in the UK: Patient Characteristics, Diagnoses and Outcomes in the 2007 UK Audit. Gut, 60, 1327-1335. http://dx.doi.org/10.1136/gut.2010.228437

[5] Rockall, T.A., Logan, R.F., Devlin, H.B. and Northfield, T. (1997) Influencing the Practice and Outcome in Acute Upper Gastrointestinal Haemorrhage. Steering Committee of the National Audit of Acute Upper Gastrointestinal Haemorrhage. Gut, 41, 606-611. http://dx.doi.org/10.1136/gut.41.5.606

[6] Vreeburg, E.M., Terwee, C.B., Snel, P., Rauws, E.A., Bartelsman, J.F., Meulen, J.H. and Tytgat, G.N. (1999) Validation of the Rockall Risk Scoring System in Upper Gastrointestinal Bleeding. Gut, 44, 331-335. http://dx.doi.org/10.1136/gut.44.3.331

[7] Ali, H., Lang, E. and Barkan, A. (2012) Emergency Department Risk Stratification in Upper Gastrointestinal Bleeding. CJEM, 14, 45-49.

[8] Lahiff, C., Shields, W., Cretu, I., Mahmud, N., McKiernan, S., Norris, S., Silke, B., Reynolds, J.V. and O’Toole, D. (2012) Upper Gastrointestinal Bleeding: Predictors of Risk in a Mixed Patient Group including Variceal and Nonvariceal Haemorrhage. European Journal of Gastroenterology Hepatology, 24, 149-154. http://dx.doi.org/10.1097/MEG.0b013e32834e37d6

[9] Rockall, T.A., Logan, R.F., Devlin, H.B. and Northfield, T. (1996) Risk Assessment after Acute Upper Gastrointestinal Haemorrhage. Gut, 38, 316-321. http://dx.doi.org/10.1136/gut.38.3.316

[10] Rockall, T.A., Logan, R.F., Devlin, H.B. and Northfield, T. (1996) Selection of Patients for Early Discharge or Outpatient Care after Acute Upper Gastrointestinal Haemorrhage. National Audit of Acute Upper Gastrointestinal Haemorrhage. Lancet, 347, 1138-1140. http://dx.doi.org/10.1016/S0140-6736(96)90607-8

[11] De Groot, N.L., Van Oijen, M.G.H., Kessels, K., Hemmink, M., Weusten, B., Timmer, R., et al. (2014) Prediction Scores or Gastroenterologists' Gut Feeling for Triaging Patients That Present with Acute Upper Gastrointestinal Bleeding. United European Gastroenterology Journal, 2, 197-205. http://dx.doi.org/10.1177/2050640614531574

[12] Salih, H.M., MIbnouf, M.A., Siddig, A.A. and Masaad, A. (2009) Rockall Score of the Acute Upper Gastrointestinal Bleeding Patients the Experience in Sudan. Sudan Journal of Medical Sciences, 4. http://dx.doi.org/10.4314/sjms.v4i3.48314 
[13] Morsy, K.H., Ghaliony, M.A. and Mohammed, H.S. (2014) Outcomes and Predictors of In-Hospital Mortality among Cirrhotic Patients with Non-Variceal Upper Gastrointestinal Bleeding in Upper Egypt. The Turkish Journal of Gastroenterology, 25, 707-713. http://dx.doi.org/10.5152/tjg.2014.6710

[14] Gonzalez-Gonzalez, J.A., Garcia-Compean, D., Vazquez-Elizondo, G., Garza-Galindo, A., Jáquez-Quintana, J.O. and Maldonado-Garza, H. (2011) Nonvariceal Upper Gastrointestinal Bleeding in Patients with Liver Cirrhosis. Clinical Features, Outcomes and Predictors of In-Hospital Mortality. A Prospective Study. Annals of Hepatology, 10, 287-295.

[15] Mohamoud, Y.A., Mumtaz, G.R., Riome, S., Miller, D. and Abu-Raddad, L.J. (2013) The Epidemiology of Hepatitis C Virus in Egypt: A Systematic Review and Data Synthesis. BMC Infectious Diseases, 13, 288. http://dx.doi.org/10.1186/1471-2334-13-288

[16] Gado, A., Ebeid, B., Abdelmohsen, A. and Axon, A. (2014) Predictors of Mortality in Patients with Acute Upper Gastrointestinal Hemorrhage Who Underwent Endoscopy and Confirmed to Have Variceal Hemorrhage. Alexandria Journal of Medicine, in Press.

[17] Kumar, A.S. and Sibia, R.S. (2015) Predictors of In-Hospital Mortality among Patients Presenting with Variceal Gastrointestinal Bleeding. Saudi Journal of Gastroenterology, 21, 43-46. http://dx.doi.org/10.4103/1319-3767.151226

[18] Anand, D., Gupta, R., Dhar, M. and Ahuja, V. (2014) Clinical and Endoscopic Profile of Patients with Upper Gastrointestinal Bleeding at Tertiary Care Center of North India. Journal of Digestive Endoscopy, 5, 139-143. http://dx.doi.org/10.4103/0976-5042.150660

[19] Balaban, D.V., Strâmbu, V., Florea, B.G., Cazan, A.R., Brătucu, M. and Jinga, M. (2014) Predictors for In-Hospital Mortality and Need for Clinical Intervention in Upper GI Bleeding: A 5-Year Observational Study. Chirurgia, 109, 4854.

[20] Sanders, D.S., Carter, M.J., Goodchap, R.J., Cross, S.S., Gleeson, D.C. and Lobo, A.J. (2002) Prospective Validation of the Rockall Risk Scoring System for Upper GI Hemorrhage in Subgroups of Patients with Varices and Peptic Ulcers. The American Journal of Gastroenterology, 97, 630-635. http://dx.doi.org/10.1111/j.1572-0241.2002.05541.X

[21] Lee, J.Y., Lee, J.H., Kim, S.J., Choi, D.R., Kim, K.H., Kim, Y.B., Kim, H.Y. and Yoo, J.Y. (2002) Comparison of Predictive Factors Related to the Mortality and Rebleeding Caused by Variceal Bleeding: Child-Pugh Score, MELD Score, and Rockall Score. The Korean Journal of Hepatology, 8, 458-464.

[22] Sarwar, S., Khan, A.A. and Tariq, S. (2008) Comparison of MELD, Child Pugh Score and Rockall Score for Predicting Rebleeding and In-Hospital Mortality in Patients of Variceal Bleeding. Journal of the College of Physicians and Surgeons Pakistan, 18, 524-525.

[23] Wang, C.Y., Qin, J., Wang, J., Sun, C.Y., Cao, T. and Zhu, D.D. (2013) Rockall Score in Predicting Outcomes of Elderly Patients with Acute Upper Gastrointestinal Bleeding. World Journal of Gastroenterology, 19, 3466-3472. http://dx.doi.org/10.3748/wjg.v19.i22.3466 